\title{
The History and Work of the Actuarial Society of Edinburgh
}

\author{
BEING \\ THE INAUGURAL ADDRESS FOR SESSION I883-84
}

BY THE HONORARY PRESIDENT OF THE SOCIETY

GEORGE M. LOW, F.R.S.E, F.F.A.

MANAGER OF THE EDINBURGH LIFE ASSURANCE COMPANY 


\section{The History and Work of the Actuarial}

\section{Society of Edinburgh.}

WHEN this Society elected its first Honorary President, and in so doing paid a fitting compliment to one who had taken the leading part in its formation, his reply to the request that he would undertake the office was, "I have never in my life received any mark of approbation and esteem which has given me greater pleasure."

I do not know that any words of mine could more fittingly express the feelings with which I received your invitation to take this Chair; but, if I were to add anything to the expression, it would be to say how sensible I am of the honour of holding a position which has been filled by so many eminent members of our profession.

If during the considerable period of my connection with the Society I have been able to show in any useful way my warm interest in its welfare, I am more than repaid by finding that I have gained in some measure your confidence and esteem.

In considering how best to discharge the duty which a timehonoured and excellent custom has associated with the office of President, I was led to think that your time might be profitably occupied in taking a glance at our past history as a Society, and at our present position, and trying to gather from the survey some useful lessons for the future.

I am well aware how unimportant the affairs of such a Society as this may appear, especially when compared with those of other bodies which occupy a larger place in public and professional estimation; but at least they have an interest and importance for ourselves, and any account of the Society which may reach beyond its own members may serve to make it better known, and to render its position and the nature of its work clearer, to those who are acquainted with it only by its name and its publications.

The subject seemed to me the more appropriate from the circumstance that the present Session will embrace the twenty-fifth 
anniversary of the formation of the Society, so that a period has arrived when it is natural to indulge in a retrospect, and to consider how we have fulfilled, and how we may yet fulfil, the objects for which we are associated.

The recent lamented death, too, of Mr. William Thomas Thomson, the virtual founder and first President of the Society, suggests a review of the history and work of an organisation in which he always took a special interest, and to which he looked, as he said at its formation, "as the basis of the future support and elevation of the profession of Actuary in Scotland."

If I enter with some minuteness of detail into facts which may seem to be trivial in themselves, and to have acquired as yet but little of the interest which gathers round even the minutiæ of longforgotten circumstances, let it be remembered that to a large proportion of those now connected with the Society the occurrences of a quarter of a century ago are far beyond recollection.

When opening the Session of the Institute of Actuaries last year, your own ex-President, Mr. Sprague, gave an account of that body, in the course of which he referred to the prominent part taken in its formation by Mr. Thomson, and to the foundation of the Faculty of Actuaries in Scotland, effected largely through that gentleman's instrumentality.

As already stated, it was to the same mind, always active and zealous in whatever tended to elevate and advance the Actuarial profession, that this Society mainly owed its origin.

The Faculty of Actuaries was constituted in January 1856, for the purpose, among other things, of "promoting the study of the Doctrine of Probabilities; of Vital Statistics and Statistics in general; of Finance, as bearing on fluctuations in the value of money; and of all cognate subjects, a knowledge of which is essential to the efficient discharge of the duties of a Life Assurance manager and actuary." In pursuance of this object several plans were adopted : courses of lectures were organised on the principles of actuarial calculations and the law of Life Assurance; a library of books was formed, the beginning of the collection to which we have all been indebted; and a series of examinations was instituted for those who desired to give evidence of their qualifications for the duties of an Actuary. But it was soon felt that something more was wanted-some further means of helping forward in their attainments those who were preparing to take their places as 
responsible members of the profession-and the Council of the Faculty took into earnest consideration what this additional means should be. The result of their deliberations was expressed in the following Minute, dated 30th December 1858, a copy of which is engrossed among the early records of the Society :-

"The Council resumed consideration of the suggestion which had been made at last meeting as to giving increased attention to the promotion of the study of those subjects connected with Life Assurance. They were of opinion that the periodical examinations, though eminently useful, did not wholly exhaust what had been intended at the formation of the Faculty. With a view to bring together the gentlemen who are engaged in Life Assurance Offices, or are proposing to follow out the profession of an Actuary, and to stimulate their progress in professional and general studies, it seemed to the Council that it would be desirable to obtain the co-operation, as widely as possible, of the gentlemen engaged in the different Life Offices and in the offices of private actuaries, which might be accomplished by the formation of a voluntary Association, having some connection with the Faculty, though not incorporated with it, which might meet at regular intervals, when papers might be read on the various subjects involved in the study of Life Assurance. With a view to organise such an Association, it was resolved that a gentleman from each Life Office in Edinburgh be requested to attend a preliminary meeting, when the subject may be considered more in detail and the views of those gentlemen who may be expected to take part in the movement ascertained. Without in the meantime indicating any of the more detailed arrangements, it was thought that the Faculty's Hall might be granted for the periodical meetings of the proposed Association, and that the Library might be made available for the use of the members."

It may be interesting to record that the members of Council present on this occasion were Messrs. Archibald Borthwick, William Thomas Thomson, William Wood, Charles Pearson, George Ramsay, George Auldjo Esson, John Macgregor M'Candlish, and Robert Balfour; the last two gentlemen having been at the time Honorary Secretaries of the Faculty.

The meeting suggested by the Council was held on 14th January 1859 , and was attended by eleven gentlemen from as many different Life Offices in Edinburgh, who heard the views of the 
Council, and afterwards consulted among themselves, under the presidency of our good friend Mr. Meikle, as to the means of carrying these into effect. As the result, a second meeting was held six days later, at which certain preliminary arrangements were made, and on 3d February 1859 the Society was formally constituted and forty-eight gentlemen were enrolled as members.

At the meeting held for this purpose a resolution was passed "by acclamation" inviting Mr. Thomson to accept the office of Honorary President. He held this position for two years, and would have been re-elected, but he himself desired that the office should be conferred on Mr. David Chisholm, one of the first two Vice-Presidents, a gentleman whose name and work are known to every Actuary. Mr. Thomson, however, again honoured the Society by becoming its President in 1866, and afterwards in 1873, shortly before his retirement from active professional life. The address he delivered from this Chair on the last of those occasions, and which he described as his "legacy to the Society," is well worthy the attention of every Actuarial student, and especially of every member of this Society. Like the first address of Mr. Thomson, it deals with a subject to which he attached great importance, and which is too apt to be neglected, in its wider aspects, by those who are chiefly concerned with the technical requirements of our profession and their everyday practical application.

The leading portion of the address, as many of you will remember, was upon "Statistical Inquiry as a leading and fundamental branch of Actuarial knowledge." I need not recall the grounds on which this subject was pressed on the attention of members of this Society, nor the claim that was made of a place for the Actuary "in every department of statistical work." Those who are not already familiar with the address should procure copies and read it for themselves. I am tempted, however, to quote one short passage, characteristic of the author's views of his profession, and of the desire for its advancement, particularly in Scotland, which he exhibited in more than one practical form :-

"I am afraid some of my brethren may think my estimate of the prospects of the Actuarial profession somewhat too highly coloured, but I am quite prepared to defend my position, and I hope that each member of the Society will strive for its elevation as an individual member of it, imbued with a deep sense of the responsibility he is undertaking. We are not a very large body 


\section{Actuarial Society of Edinburgh.}

in Scotland, so we should be enthusiastic in our cause, united in our membership, and high in our aims."

Other two of our past Presidents have been removed by death, leaving names which will long be cherished and honoured among us-Mr. Samuel Raleigh and Mr. David Maclagan. They, too, in their professional career, as well as in their addresses from this Chair, set before their younger brethren a high standard, both of mental attainment and of personal excellence.

Of the gentlemen who were present at the formation of the Society only seven now remain on the roll of members, and it is a fact worth mentioning that they all now hold official positions in Life Offices, some of them very important positions indeed. Who shall say how much influence this Society may have had in developing the qualities which have served to elevate those gentlemen in their profession? Their continued membership, and that of others who, like them, have passed into the maturer stage of their career, is an honour to the Society, and it is perhaps no less a credit to the gentlemen themselves, as showing that they retain an interest in the welfare of an association from which they derived advantage in earlier days, and which is now conferring similar benefits on a new generation.

Of the remaining forty-one original members, some have died, others have ceased to be connected with our calling, and not a few who still remain in it have withdrawn from the Society since they could no longer be ranked among the younger members of the profession.

Since the commencement, the total number of members enrolled has been no fewer than 370. From obvious causes there have been numerous withdrawals and constant fluctuations in the membership, but there is still a goodly number on the roll,-159. Indeed the Society has not at any time suffered from lack of members. The terms of admission have wisely been made so easy that no one who felt it his interest to join has found any obstacle, and consequently a large proportion-perhaps I might even say the great majority-of the gentlemen in our Offices who have had any ambition to rise in the Actuarial profession have become members. In this respect, therefore, the Society has been abundantly successful. It has attracted to itself the bulk of the class for whose sake it was instituted.

How, then, has it benefited its members? In what ways, and to 
what extent, has it fulfilled the aim of "stimulating their progress in professional and general studies"? What has it done for the advancement of the profession?

It would seem that any efforts to connect with the Society plans of a distinctly educational character have not been attended with success. A proposal, for example, was made at one time that the Committee of Management should organise periodical meetings at which students might bring up any difficulties they had encountered and have them discussed and explained; but this did not meet with support.

It has been chiefly by the means originally contemplated at its formation-by holding stated meetings for hearing and discussing papers prepared by its members and others-that the Society has been useful. Some of those papers have been printed, and have been welcome contributions to the literature of our subject. Of these I shall speak hereafter.

Down to the close of last Session, the Society had held in all 143 meetings, at which 154 contributions of different kinds had been made to its proceedings,-Addresses, Lectures, Debates, and Papers on various subjects.

It occurred to me that an interesting view of the character of those proceedings might be obtained by classifying the various contributions under general heads, according to the nature of their subjects. The following is the result :-

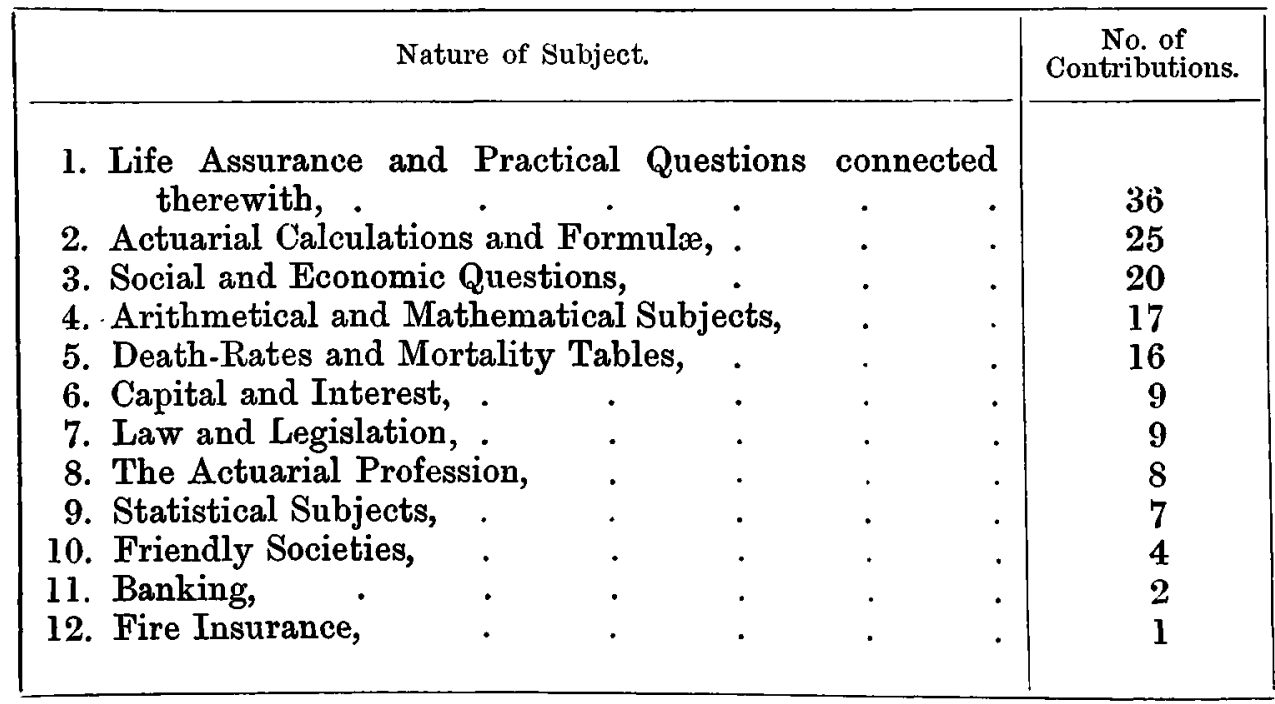

The range of subjects is very much what one would have wished and expected, and is quite in accordance with the objects 
of the Society as defined in the Laws, namely, "First, The promotion of the study of the principles of Life Assurance and of Assurance against other contingencies; Second, The consideration of all subjects to which the Doctrine of Probabilities may be applied, as well as of the best methods of collecting and applying Vital Statistics; and Third, The consideration of questions bearing on Social Science or Political Economy."

Quite properly and naturally, the foremost place is occupied by the endless variety of theoretical and practical questions connected with Life Assurance, and there is at least a representation of most of the other subjects which have a bearing on Actuarial science and practice.

I have been struck, however, with the fact that in recent years there has been a marked tendency to concentrate attention more and more upon what may be called purely professional subjects, as distinguished from those of a wider and more general character. This is shown by the following Table of the Proceedings during the last five years, 1878 to 1883 :-

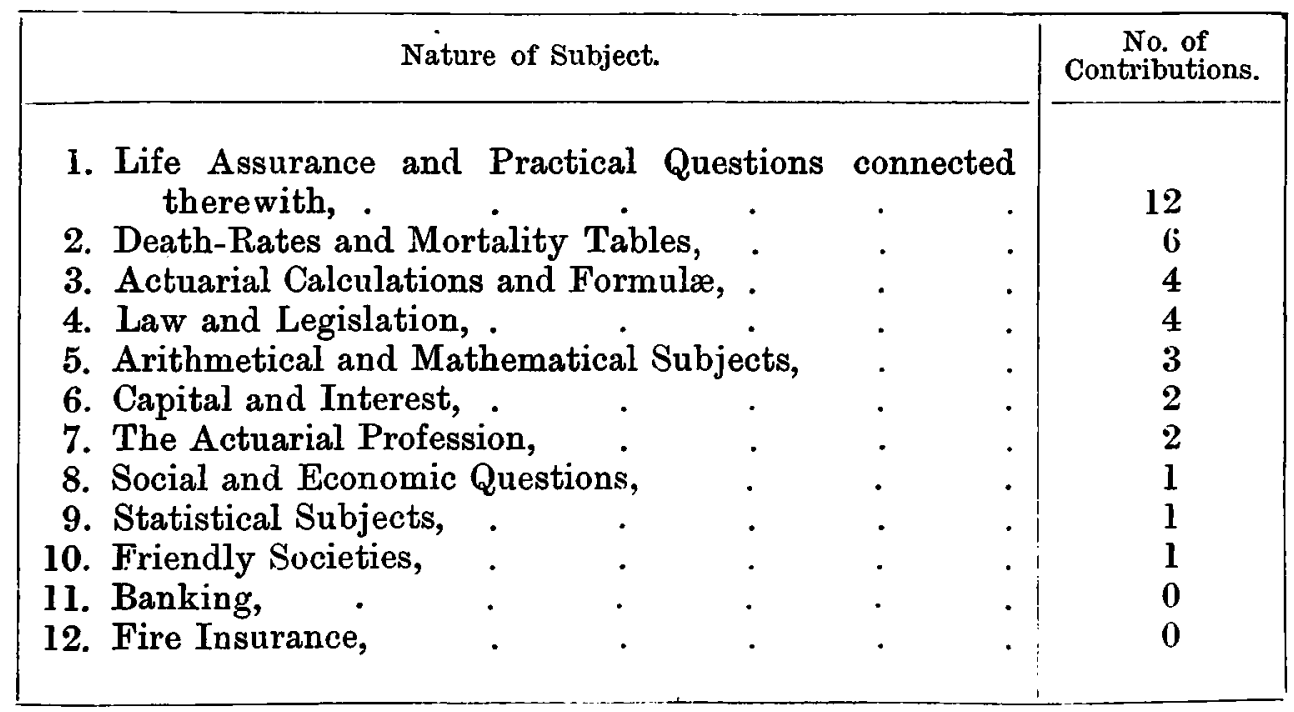

It will be seen that some of the subjects have changed their places in this list as compared with the other. In particular, the subject of "Death-Rates and Mortality Tables," instead of being fifth in the list, is now second, while the class of "Social and Economic Questions," which formerly held a prominent position in the order of frequency, is now very low in the scale. The greater prominence given to the former class of subjects in these recent years has no doubt been due to the increased attention 
lately bestowed on questions of "selection" and such like, suggested by the Twenty Offices' Experience. So far the circumstance may be hailed with satisfaction, as an indication that the Society's proceedings have been moving in the line of current thought. But the comparative neglect of Economic and Social questions, of a kind suitable for discussion here, does not admit of so satisfactory an explanation.

On the whole, I am disposed to think that the apparent tendency to narrow the range of subjects brought before the Society is somewhat to be regretted. I by no means wish to minimise the advantage of close attention being given to those subjects which are more intimately related to your professional studies and your business experience. I think that nothing should ever occupy so prominent a place in the proceedings of this Society as the discussion of points of theory and practice, calculated to be useful in Actuarial pursuits or in the business of Life Assurance, and I even rejoice to see that the number of contributions on such subjects has been steadily increasing. This has been the result, in some measure, of the invitation your Committee of Management have been wise enough to hold out for brief "notes" on points which do not well admit of being expanded to the dimensions of a paper. These notes are calculated to be of great interest and value, and I cannot help thinking that, if they were still more frequent, the meetings would gain in attraction and every one would be benefited. But it will be very unfortunate if increased activity in this direction tends to exclude from the Society's proceedings those wider subjects to which I have alluded. It is just one of the dangers that beset a Society whose members are associated on the basis of a common profession, that the proceedings may become narrowed down to matters which lie in the direct line of the members' studies and their daily experience. This is a danger you cannot too zealously guard against. If the Society is to aid in fitting its members-as it has already aided in fitting not a few-for the higher duties and more responsible positions connected with their calling, it should lead them to take broad and elevated views of the profession of an Actuary-to see how it bears upon subjects of wide and general interest, lying beyond its own mere technical domain.

I have already reminded you of the high importance assigned by a late distinguished ex-President to one of those wider subjects 
-that of General Statistics, as distinguished from the limited practical question of Death-Rates. Unquestionably this is a field in which actuaries are peculiarly fitted to engage, and in which young actuaries in particular may employ themselves with the greatest advantage. It offers a rich reward for their labours, not only in the practical results that may be arrived at, but in the training and mental discipline which a well-conducted statistical inquiry of any kind is calculated to afford. I think it would be well if papers on statistical subjects were more frequent in your proceedings, and if members of the Society were more alive to the advantages of engaging in this branch of inquiry.

Again, your attention has been too seldom directed-more seldom in recent years than formerly-to the wide range of social and economic questions which have a more or less direct bearing on our pursuits, and to those questions of interest and capital, of banking and currency, a proper understanding of which is so important to every one engaged in financial operations.

Perhaps this has been due in some measure to the fact that the Faculty of Actuaries has given but little prominence to such subjects in its scheme of examinations. Those examinations, as at present conducted, are intended to test the acquirements of students in purely professional subjects ; and the collateral branches of knowledge, of which the mature actuary or Life Assurance manager so well knows the value, are not regarded as falling strictly within their domain. It is not for a moment to be supposed, however, that the importance of such wider studies is underestimated by the Faculty. Some of its members have thought it would be desirable to alter the plan of the examinations, so as to give them a wider range and to include some of the subjects of which I have been speaking; but this is a question on which there seems to be room for difference of opinion, and hitherto the opposite view has prevailed. Doubtless the existence of this very Society has been regarded as superseding, to some extent, the necessity for subjecting students to examination in a class of subjects so much less fitted for such a test than those immediately connected with our own science. The Faculty, at all events, has given ample evidence of its desire that such subjects should be cultivated here. Its most prominent members have again and again from this Chair urged them on your attention; and when the Council resolved, some years ago, to bestow a sum for prize competition within the 
Society, it was stipulated that the essays should be on "some economic subject."

It strikes one as not a little remarkable that only once-and that in a President's address-has the subject of Fire Insurance been in any direct way brought before the Society. We have had many members connected with that important branch of insurance, but apparently no one has thought it suitable to bring up a paper on any department of the subject for discussion here. I do not, indeed, think that the details and technicalities of Fire Insurance are altogether suitable subjects to occupy your attention, or that they would tend to expand your minds in the directions in which you, as actuaries, should strive after mental attainment. But surely some of the principles underlying the subject-some of the special applications of the Law of Average which it involves-or some statistics, if these be available, showing the measure of the risks incurred-might be deemed suitable for your consideration. Our friends the Insurance and Actuarial Society of Glasgow, in whose prosperity we all take a warm interest, have adopted a wider platform than ours-wider, indeed, than it was necessary, or perhaps even desirable, for ours to be, so far as practical business matters are concerned-and the subject of Fire Insurance seems not unlikely to occupy a large place in their proceedings. Perhaps the younger Society will be able to show how you may profit by working in this field.

I suppose it is always the case in associations of this kind that the number of members who take an active share in the work is comparatively small. At all events our own Society has been no exception to the rule, only about one in six of the ordinary members having contributed papers of any kind. I find that the whole contributions which have been laid before your meetings since the commencement have been the work of 76 persons-of whom 13 were Honorary Presidents and non-members, and 63 were ordinary members of the Society. Thirty-six of the contributions were by the former class, and 118 by the latterso that, on the average, each of the 63 contributing members appeared twice before the Society.

No doubt a number of members have taken part in the discussions who have not themselves brought forward papers, but still there is room for regret that the non-contributors have formed 
such a large majority. It is the working members who derive most benefit from being connected with a Society like this. Those who merely listen to papers as they are read, and who do not even join in criticising or commenting upon them, may certainly gain information, but they as certainly miss many advantages that are to be gained by taking an active part in the proceedings. The preparation of a paper demands a certain amount of thought and research, and is sometimes the most effectual means of widening and rendering more accurate one's own knowledge of the subject taken in hand. Those who undertake to criticise it must, in order to do so intelligently, make themselves familiar with the subject of which it treats, and thus they may both increase their own knowledge and extend or correct that of others. The habits, too, of rapid thinking and correct speaking, so serviceable in every department of life, are best cultivated by engaging in discussions such as those of this Society ought to be.

These considerations, it will be seen, are independent of the higher motives which should impel every one to endeavour to be useful to those with whom he is associated. You are all familiar with the Baconian maxim which appears on the title-page of the Journal of the Institute of Actuaries. I need not repeat it. You know that the object of your associating together is to receive and to impart help in your common studies and business experiences.

I would say, then, to every member of the Society, Have you in the course of your studies received fresh light on any subject? Have you conceived any new idea that may be useful to your brethren? Have you in your business experience lighted upon any fresh problem, any new point of practice? Are you desirous to improve your own knowledge of any subject, however remotely connected with Actuarial science? Finally, are you desirous to fulfil your obligations to your fellow-members? Then make it your duty to contribute something, be it much or little, to the proceedings of the Society. Feel that the Society is entitled to this-that it is your interest as well as your duty to make its meetings instructive and useful, since in proportion to its success in that respect will be the benefit you yourself will derive from it. Do not be afraid of criticism. Your efforts will be sure to meet with generous appreciation, and if your fellow-members do not agree with what you say, they will, according to my experience, state their dissent, and their reasons for it, in courteous and kindly terms. 
I would say also to one and all, Do not be backward to take part in the discussions, however little you may be able to contribute to them. Besides being advantageous to yourselves, it is the most acceptable return you can make to those who take the trouble of writing papers, to show in this way that they have succeeded in arousing your interest. Sometimes, no doubt, the subjects are of such a nature as to leave but little room for criticism or remark beyond what is pretty sure to be occupied by the first one or two speakers in a discussion. But no subject presents itself to any two minds in precisely the same light, and even the minuter shades of difference in the views that may be taken are capable sometimes of helping the elucidation of a subject. Besides, it is by no means necessary to a profitable discussion that it should be confined to points actually suggested by the essayist, or dealt with in his paper. What is wanted is not so much to analyse the paper read as to exhaust the subject with which it deals.

The older members of the Society-gentlemen with whom it has been my honour and privilege to be associated for years-will perceive that some of these observations are not addressed to them. They will, I hope, pardon my having occupied their time by dwelling on points which they and I doubtless agree in thinking well worthy of the attention of our younger brethren.

One important branch of the work accomplished by and through the Society remains to be noticed.

Early in our history the Council of the Faculty of Actuaries very generously undertook to print for the benefit of our members a short series of papers which had been read to them by Mr. Meikle. This publication became well known as "The Rationale of Life Assurance Premiums." Its reprint as one of our new series of Transactions is an evidence of the high appreciation it has met with among Actuarial students.

At irregular intervals afterwards the Society printed, with occasional help from the Faculty, or from the authors themselves, some of the Addresses of its Honorary Presidents, and several papers which were considered specially calculated to be useful. The following is a list of them, so far as I have been able to make out, up to the time when the new series was begun :-

"On the Position and Objects of the Profession of an Actuary." Address by Mr. Samuel Raleigh as Honorary President. 1863. 
"An Analysis of the Profits of Life Assurance." By Mr. Meikle. 1865.

"The Future Interest of Money, considered chiefly as an Element in Life Assurance Calculations :" President's Address by Mr. John M. M`Candlish. 1865.

"The Education of an Actuary:" President's Address by Mr. David Maclagan. 1867.

"The Valuation of Life Contingencies by the help of Analytic Functions." By Mr. Edward Sang,-a gentleman, let me say in a word, to whom this Society and the Actuarial profession are under many obligations. 1869 .

Address by Mr. Meikle as Honorary President. 1869.

"Capital, Money, Interest, and Investment:" President's Address by Mr. Andrew Hugh Turnbull. 1870.

"Policy Life-Lines: The Relation of Tables of Mortality to Values of Policies." By Mr. Meikle. 1871.

"Fire Insurance : " President's Address by Mr. M`Candlish. 1872.

"On the Usefulness of Mathematical Studies to the Actuary :" President's Address by Mr. T. B. Sprague. 1874.

"On the Additional Premium required for Residence in Foreign Climates :" President's Address by Mr. Meikle. 1875.

"On some Problems in the Calculus of Finite Differences." By Mr. W. R. Macdonald. 1876. This paper, the last of the earlier series of publications, was, like one or two of the new series, intended specially for the benefit of students of the Faculty of Actuaries, by whom it has been well appreciated.

The Address by the late Mr. W. T. Thomson at the opening of Session 1873-74, to which allusion has already been made, was kindly printed by that gentleman for the use of the members.

In the same way Mr. Spencer Thomson was good enough to present the Society with printed copies of his Address on "Selection" delivered in 1877.

The new series of Transactions was begun in 1879. It had been felt to be matter for regret that while publications of permanent interest and value had been issued from time to time under the auspices of the Society, they had not been produced in a form convenient for binding and reference. It was therefore decided to print. future papers in a uniform style and size, consecutively paged, and to issue a title-page and index when sufficient numbers 
have been printed to form a volume. The Society is not in a position to keep up a regular periodical issue of such publications, and in the meantime only those papers are being printed, besides the Presidential Addresses, which appear to be of special interest or value.

The numbers issued up to the present time are :-

No. 1. "On the Fifth and Sixth Schedules of the Life Assurance Companies Act 1870 :" President's Address for 1878-79, by Mr. David Deuchar.

No. 2. "On Joint-Life Annuities." By Mr. J. J. M'Lauchlan.

No. 3. The reprint of Mr. Meikle's "Rationale of Life Assurance Premiums" already alluded to.

No. 4. "On the Comparative Amount of Reserves obtained by Valuations on different approved Tables of Mortality, and at different Rates of Interest :" President's Address for 1879-80, by Mr. A. H. Turnbull.

No. 5. "Practical Notes on the Training and Duties of an Actuary:" President's Address for 1880-81, by Mr. Thomas Marr.

No. 6. "Note on War Mortality in Recent Campaigns." By Mr. A. G. Mackenzie.

No. 7. "On Money and the Future Rate of Interest:" President's Address for 1881-82, by Mr. Adam Gillies Smith.

No. 8. "The Theory of Finance." By Mr. George King.

The ninth number of the series, being the Address by Mr. Sprague at the opening of last Session, will soon be issued.

Besides those which have been printed by and for the Society, several of the papers read here have, through the courtesy of the Editor of the Journal of the Institute of Actuaries, found places in that invaluable periodical.

The mention of the Society's publications recalls once more the close relationship between us and the Faculty of Actuaries in Scotland, and demands a grateful acknowledgment of the assistance and encouragement we have always received from that body. At the outset the Faculty not only opened its Library to our members, but gave the use of its Hall for our meetings, and for a considerable time defrayed the incidental expenses. For many years past the Faculty and the Society alike have been indebted for accommodation to the Company in whose rooms we are now met. This was one of those acts by which the late Mr. 


\section{Actuarial Society of Edinburgh.}

Thomson laid his profession under lasting obligations, and its continuance down to the present time is a privilege for which we cannot too warmly express our thanks to the Manager and Directors of the Standard Assurance Company.

Not the least important aid rendered by the Faculty to the Society has been the granting of money towards the cost of our publications. But for the assistance of the Faculty, indeed, we could not have undertaken to issue some of those papers which have been found so helpful by Actuarial students, so that in reality those who have benefited by them owe their thanks no less to the Faculty than to the Society.

I have already had occasion to allude to another plan by which the Faculty sought to promote your interests-namely the presentation of Prizes for competitive essays by your members. The Society itself voted a sum for this purpose in the year 1862, when the prize was gained by a gentleman, then a young member, but now well known as a successful insurance manager, who five years ago addressed you from this Chair as your Honorary President.

In 1866, however, the Council of the Faculty resolved to devote a sum "as a prize to the members of the Actuarial Society for the best essay on some economic subject to be fixed by the Committee." The subject chosen for this competition was "The Influence of the recent Gold Discoveries on the price of Labour and Commodities." The gentleman who gained the prize on that occasion now holds the position of chief officer of one of the old Insurance Companies in London.

In the following year the offer of a prize was renewed, but there was no competition, and the liberal proposal of the Council has not since been taken advantage of. This, I think, is much to be regretted. It is beyond question that the members would benefit greatly, and the Society's proceedings would derive increased value, if such a competition were engaged in every year, and the best of the essays were read and criticised at the meetings, as was done with excellent effect on the two occasions I have referred to. The gaining of the prize, too, would be an enviable mark of distinction, and there would thus be a useful stimulus to the study of the prescribed subjects. I cannot, of course, undertake to say whether the Council would now be disposed to renew their offer. Perhaps they might be induced to do so if evidence were given that it would be appreciated; and I cannot but think, 
in view of the increased membership of the Society, that an annual competition of this kind might easily be sustained.

The record I have been able to present of the career of this Society, and of the work accomplished by its members and under its auspices, is one on which you may fairly look back with some degree of complacency and satisfaction. Indeed, considering that the Society has always been composed mainly of the younger members of our profession, and that its stated income has been limited to a merely nominal annual subscription, the results may even be regarded as highly creditable.

Those who have watched your history, and have been familiar with the papers read and discussed at the meetings, cannot have failed to be impressed with this fact, that the style of those contributions-what may be called their scientific character-has, on the whole, become sensibly higher. Whether this is an unmixed benefit in a Society intended to be helpful to those who are still in the student stage may possibly be questioned. May it not happen that the less advanced members listen-or, what is worse, stay away from listening-to a paper aimed too high for them, when they might have derived benefit from one of a simpler and more elementary character?

This touches a question which cannot but arise at this stage of the Society's career.

During the quarter of a century that has elapsed since the Actuarial Society began its operations, the science of Life Contingencies and the theory and practice of Life Assurance have made great advances.

The Society itself has happily not been stationary, but, on the contrary, has made very decided progress.

Not a few of its members, who have passed or who are passing out of the junior ranks of the profession, still retain their connection with the Society and take an active share in its proceedings.

And, finally, no other Society has arrangements under which those more advanced members could exercise the gifts they have been accustomed to display here.

The result of the combined operation of all those causes is that the Society has moved to some extent from its original position, and seems tending. to become rather a Society of Actuaries 


\section{Actuarial Society of Edinbuigh.}

than an Actuarial Society in the sense that was intended at its formation.

Is the Society not in danger, then, of having its proper function obscured, and of drifting into the exercise of functions of a higher kind, which would be more efficiently, as well as more appropriately, performed by a body possessed of larger means and composed of members more advanced in actuarial knowledge and experience?

I confess this question is one which has frequently presented itself to me, and which I have sometimes been disposed to answer in the affirmative. There is a danger, in my opinion, that the Society's usefulness may suffer to some extent if the subjects discussed are of too advanced a character, or if they are treated in a style beyond the comprehension of a large section of its members. Those gentlemen may become discouraged from attending the meetings, and may lose their interest in proceedings which ought to be conducted largely for their benefit.

Still, I am by no means disposed at present to suggest that any check should be put on the higher class of contributions which the Society is privileged to receive. On the contrary, it seems to me it would be a grievous misfortune to us in Scotland if we had no channel of our own for bringing work of that nature before the profession, and as things now stand, I, for one, regard it as matter for congratulation that this Society is the channel for so much that is valuable and instructive. But it is not disparaging to say that a more appropriate channel might be found. I cannot help thinking the time may come when the Faculty of Actuaries will take into its own hands some of the work that is now performed here,-will begin to hold meetings for the discussion of actuarial topics, and will perhaps publish under its own immediate auspices papers such as those it now aids us with the means of bringing out in our name.

The course of events seems to me to tend in that direction. There are not a few members of the Faculty who in years past made useful contributions to this Society's proceedings, but who have outgrown their connection with you and have ceased to attend your meetings; and there are still on your roll of active membership a number of gentlemen who are well fitted to take part with their older brethren in the Faculty in discussing advanced questions of practical and scientific interest. As the numbers of 


\section{History and Work of the Actuarial Society.}

those two classes increase, the want will be more and more felt of an organisation under which they could meet for such an interchange of views. Should the Faculty hereafter move in this direction, there is no doubt that those who have been most active in the proceedings here will be found the chief contributors to those of the Faculty.

Meanwhile, let this Society go on unchecked. Let it by all means encourage its junior members to bring forward original papers and to take part in its discussions; let it chiefly encourage the production of papers and the promotion of discussions likely to be useful to the younger members of the profession; but, as matters now stand, let no one have occasion to feel that his production is too good, or its subject too far advanced, to be brought before the Actuarial Society of Edinburgh. 